ORIGINAL ARTICLE

\title{
Reducing absenteeism in hospital cleaning staff: pilot of a theory based intervention
}

\author{
S Michie, B Wren, S Williams
}

Occup Environ Med 2004;61:345-349. doi: 10.1136/oem.2003.009639

See end of article for authors' affiliations

.....................

Correspondence to:

Dr S Michie, Centre for

Outcomes Research and

Effectiveness, Department

of Psychology, University

College London, London

WCIE 7HB, UK;

s.michie@ucl.ac.uk

Accepted

5 September 2003

\begin{abstract}
Aims: To develop, pilot, and evaluate a workplace intervention to reduce sickness absence, based on a demand-control-support model of job strain.

Methods: Changes in the working arrangements of hospital cleaning staff were introduced with the aim of increasing their control over work and the support received at work. The study design was quasiexperimental, with 221 cleaning staff in the intervention group and 91 catering staff in the control group. The dependent variable was the difference in percentage monthly sickness absence between the 12 months preceding and following the intervention. Differences in sickness absence between staff groups for each month after the intervention were compared with differences between staff groups for the equivalent month one year prior to it.

Results: There was a significant reduction in the difference in sickness absence rates between the intervention and control group of $2.3 \%$ in the six months after the intervention, compared to the six months before. The difference was not maintained at 12 months.

Conclusions: These results suggest that a workplace intervention aimed at increasing control and support at work has a small effect on reducing sickness absence among hospital cleaning staff in the short term. Future research should seek to replicate this effect in larger, experimental studies, analyse postulated mediators of such theory based interventions, and develop interventions that maintain improvement.
\end{abstract}

$\mathrm{T}$ hose who work in the health sector experience high levels of sickness absence. ${ }^{1}$ This is a problem both for the staff concerned and for the organisations providing health care. The UK national health service (NHS) is a good example of this problem. Whereas UK industry overall averages a sickness absence rate of 3.7\%, the average NHS rate is at least $5 \%$. This is higher than other, equivalent occupational groups in the $\mathrm{UK}^{2}$ and in other European countries and Canada. ${ }^{3}$ In 1998, it was estimated that the cost of sickness absence in the NHS was over $£ 700$ million a year, and a reduction of one percentage point could save over $£ 140$ million annually. ${ }^{1}$ The UK government set targets that year for the reduction of sickness absence in the NHS of $20 \%$ by 2001 and $30 \%$ by $2003 .{ }^{4}$

A traditional approach to reducing sickness absence is to address this at the individual level. Strategies include returnto-work interviews, attendance monitoring, and referral to an occupational health service. There is little evidence of the effectiveness of these practices. There is, however, some evidence for the effectiveness of organisational approaches to reducing sickness absence. ${ }^{5}$ Attending work has been shown to be related to the physical and psychosocial conditions of work, ${ }^{67}$ management attitudes and behaviours, ${ }^{8}{ }^{9}$ social norms and economic pressures, ${ }^{10}$ as well as perceived health, ${ }^{7}$ and job satisfaction. ${ }^{11}$

Lower employment grade has been found to be associated with both short term and long term sickness. ${ }^{12}$ Differences in sickness absence rates between countries and between workforces with similar socioeconomic profiles within a country suggest that work characteristics predict sickness absence behaviour. ${ }^{11}{ }^{13}$ Those who perceive their jobs to be low on control, low on variety and use of skills, low on support at work, and to have a slow pace show high rates of absence. ${ }^{14}{ }^{15}$ Lower grade employees were up to six times more likely than those in higher grades to report jobs low in demands, control, and support. ${ }^{14}$ They are also more likely to have short, long, and very long spells of sickness absence. ${ }^{16}$ In another study there was a strong employment grade gradient in the rates of both short and long spells of sickness absence. These rates varied in men and women with a ratio of rates of spells of sickness absence for the lowest grade compared to the top grade of 6.1 for short spells and 6.6 for long spells in men, and corresponding figures for women of 3.2 and $3.7 .^{17}$

A frequently cited model drawing on such evidence is Karasek and Theorell's demand-control model of work related strain. ${ }^{18} 19$ According to this model, risks to health are most likely to arise when high job demands are coupled with low decision latitude (that is, low personal control over work and limited opportunities to develop skills). Decision latitude has been found to be a stronger predictor than demand. ${ }^{20}$ The model has been extended to include social support at work as a predictor of job strain. ${ }^{21} 22$

The demand-control-support model is a useful framework for planning organisational interventions to reduce job strain and associated behaviour such as sickness absence. Although there is evidence of the interaction effect between demand and control on sickness absence, ${ }^{23}$ there is a paucity of interventions developed on the basis of this theory. ${ }^{24}$ This study assesses the feasibility of introducing an organisational intervention to reduce sickness absence based on the demand-control-support model in a busy, inner-city teaching hospital, using routinely collected data to evaluate its effectiveness. It targets a group of health service staff, cleaners, who have high rates of sickness absence and ill health..$^{25}$

\section{METHODS}

\section{Design}

The study design was quasi-experimental, with outcome data collected one year retrospectively and one year prospectively for the intervention and non-equivalent control groups. 
Main messages

- The demand-control-support model of job strain provides a useful framework for the development of organisational interventions to reduce sickness absence.

- Organisational interventions aimed at modifying work characteristics are appropriate for, and acceptable to, health service managers and staff.

- A workplace intervention aimed at increasing control and support at work in hospital cleaners can reduce sickness absence levels in the short term.

\section{Participants}

The intervention group comprised all cleaning staff working for an inner-city acute hospital, with all catering staff working at the same hospital serving as the control group. A total of 221 cleaning staff and 9l catering staff were in employment at the midpoint of this two year study. Staff turnover in these groups was high. In the cleaning service it was $25 \%$ in the first year and $18 \%$ in the second year of the study. The equivalent figures for the catering service were $43 \%$ and $21 \%$ respectively. A core group of 141 cleaning staff and 57 catering staff were in post continuously throughout the whole study period.

The mean age of cleaning services staff was 46.6 years (range 20-66 years), and the mean length of service was 7.1 years (range 1 month to 30 years). Fifty six per cent of cleaning staff worked full time. There were many different ethnic groups represented in this staff group and, for the majority, English was not their first language. The catering service is under the same management arrangements, staff pay, and grading as the cleaning service and is similar in terms of the physical nature of the work. The age and ethnic profile of catering staff is similar to cleaning staff, as is the mean length of service. Sixty six per cent of catering staff worked full time.

\section{The intervention}

In the light of a $9 \%$ sickness absence rate for cleaning staff, the cleaning services manager sought the help of the hospital's occupational health unit. Assessment revealed that cleaning staff tended to work in isolation in the areas they cleaned: wards, departments such as outpatients, and nonclinical areas such as offices, toilets, and corridors. They were not part of teams and had little control over the structure of their day. They were assigned a supervisor but did not report into or out of work and therefore had no routine daily contact with other colleagues or managers. There was no system for getting help with problems, such as occasional incidents of harassment from other hospital staff. There was no designated rest facility in which staff could take a break and socialise. There were reports of cleaning staff eating their lunch on ward corridors or under the stairs. Many did not attend the staff restaurant, which did not provide culturally appropriate food.

Two key elements identified in the demand-controlsupport model were missing: perceived control over work and support at work. A package of changes was designed to increase these. A process of consultation with relevant managers, the cleaning staff, and their trade union was undertaken to gain support for this intervention.

Five steps were taken to increase feelings of control over work:

\section{Policy implications}

- Further research is needed into the components of successful organisational interventions to reduce sickness absence, and the factors that may mediate and maintain initial reductions in sickness absence rates.

- The collection of sickness absence data in large organisations such as the NHS would benefit from more reliable and standardised hospital records to allow for multicentred and adequately powered trials of organisational interventions.

- Introduction of a system to report problems and request help daily, with a view to receiving help and support to deal with problems

- Management consultation with staff over a new uniform, seeking views about preferred design and colour

- Agreement that time for changing into and out of uniform be within work time

- Funding of an annual Christmas party, to be organised by the staff

- Giving a choice of timing of the morning and lunch breaks.

Three changes aimed to increase social support were:

- Establishing a system of reporting into, and out of, work to increase staff contact with each other and with supervisors

- The opening of a dedicated recreation room

- The extension of the morning coffee break from 15 to 30 minutes to allow staff time to leave their work areas for breaks in order to use the recreation room.

To maximise impact, these changes were introduced into the service within the same month.

\section{Outcome measure}

The outcome measure was the total monthly sickness absence rate expressed as a percentage. Sickness absence rates are recorded routinely by managers, using hospital records. For the purpose of this study, the following definition of sickness absence was used: hours lost due to certified and self certified sickness absence/contracted hours. This definition includes time lost through industrial injury or disease, road traffic accidents, and medical suspension, and includes those on half or no pay. It excludes partial shift absences, and hospital and dental appointments, and no adjustment is made for annual, maternity, or carers' leave. This formula was developed as part of a project to assure the reliability of NHS sickness absence data. ${ }^{26}$

\section{Analyses}

The percentage monthly sickness absence figure for each staff group was used as the unit of analysis and was available for each calendar month 12 months before and after the intervention. Analyses were conducted for the total cleaning and catering staff groups (all staff who were part of the service at each monthly time point) and for the subset of staff ("core group") employed continuously for the total study period

\section{Seasonal variation trends}

Calendar months were grouped into four three-month seasons. The dependent variable was mean sickness absence for each three-month period. Analysis of variance investigated the effects of season on sickness absence, controlling 
for the effect of whether the intervention had taken place (by creating a variable which took the value 0 for all months before the intervention, and 1 for all the months after the intervention). No significant seasonal trends were found in catering staff or the core group of continuously employed catering staff. There was, however, higher sickness absence in autumn and winter than spring and summer for all cleaning staff $(\mathrm{F}=4.89, \mathrm{df}=3,16, \mathrm{p}=0.013)$.

Within group comparison of pre- and postintervention rates

Due to the observed seasonal variation in sickness absence rates, differences in monthly sickness absence rates before and after the intervention were analysed by paired samples $t$ tests. In order to control for the observed seasonal variation, each month in the pre-intervention period was paired with the equivalent month post-intervention in both the cleaning and the catering service. This was done for both six and 12 month periods before and after the intervention.

Between group comparison across the 24 months of the study

The difference in absence rate between staff groups was calculated for each calendar month, giving a difference score for each month of the study period. Paired sample $t$ tests tested the hypothesis that these difference scores are reduced post-intervention compared to pre-intervention.

\section{RESULTS}

Table 1 and fig 1 show monthly sickness absence rates for cleaning and catering staff.

\section{Total group}

\section{Within group comparison}

There was no significant difference in sickness absence rates pre- and post-intervention within either the cleaning or the catering staff group over six months $(t=1.46, \mathrm{p}=0.205$, $\mathrm{df}=5$; and $t=0.66, \mathrm{p}=0.536, \mathrm{df}=5$ respectively), nor over 12 months $(t=0.80, \mathrm{p}=0.443, \mathrm{df}=11 ; \quad$ and $t=1.267$, $\mathrm{p}=0.235, \mathrm{df}=11$ respectively).

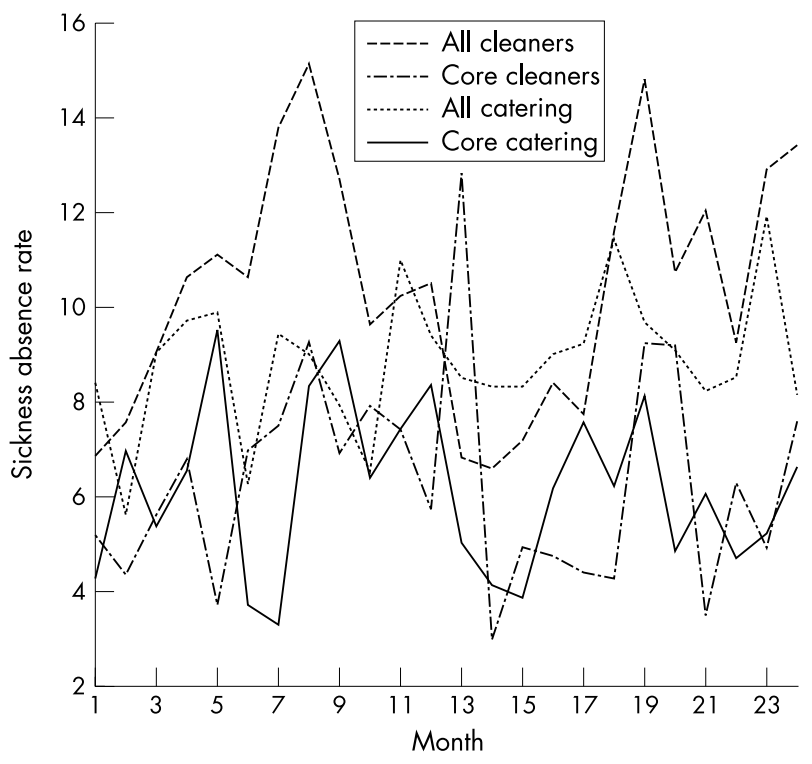

Figure 1 Percentage sickness absence rates 12 months pre- and post-intervention. Intervention in month 12. Intervention was during month 13.

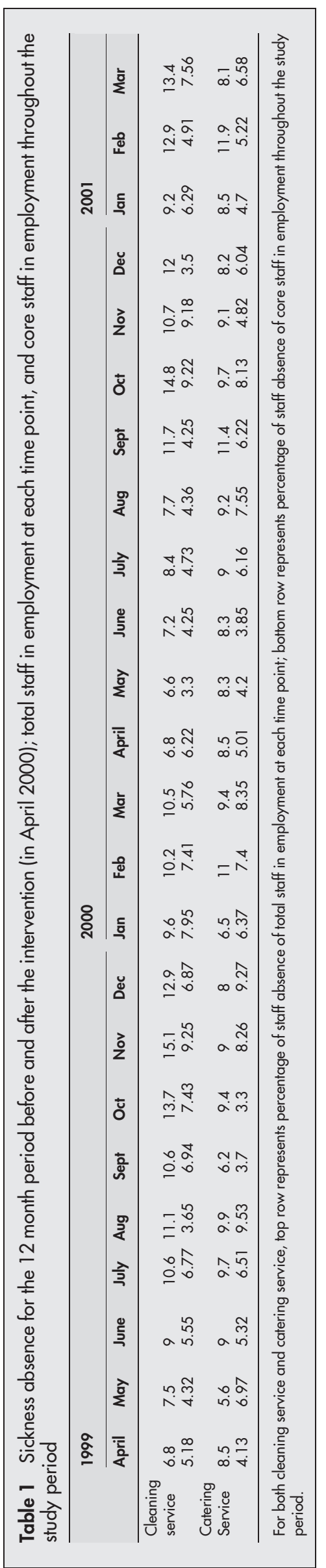




\section{Between group comparison}

There was a significant change in the difference between the cleaning and catering groups when the six months after the intervention were compared to the same period in the preintervention year $(t=3.66, \mathrm{df}=5, \mathrm{p}=0.015)$. Before the intervention, the cleaning services sickness absence was higher than that of the catering service, but this difference had narrowed by $2.3 \%$ in the six months after the intervention. There was, however, no significant difference in the levels of mean difference between the two staff groups when the 12 month period before the intervention was compared with the 12 month period following the intervention $(t=1.34, \mathrm{df}=23, \mathrm{p}=0.205)$.

\section{Core group}

\section{Within group comparison}

There was no significant difference in sickness absence rates pre- and post-intervention within either the cleaning or the catering staff group over six months $(t=1.82, \mathrm{p}=0.128$, $\mathrm{df}=5$; and $t=-0.96, \mathrm{p}=0.389, \mathrm{df}=5$ respectively) nor over 12 months $(t=1.50, \mathrm{p}=0.16 \mathrm{l}, \mathrm{df}=11 ;$ and $t=1.24$, $\mathrm{p}=0.240, \mathrm{df}=11$, respectively)

\section{Between group comparison}

There was no significant change in the difference between the cleaning and catering service when the six months after the intervention were compared to the same six month period in the pre-intervention year $(t=0.15 \mathrm{l}, \mathrm{df}=5$, $\mathrm{p}=0.886$ ) or when the 12 month period before the intervention was compared with the 12 month period following the intervention $(t=-0.249, \mathrm{df}=23, \mathrm{p}=0.808)$.

\section{DISCUSSION}

This paper describes the development of a theory based organisational intervention to reduce sickness absence in cleaning staff of an NHS acute hospital. The intervention used the framework of the demand-control-support model of job strain to promote increased control and support at work for this staff group. The results of the study suggest a small effect of the intervention over a six month period, although the turnover within the two groups precludes firm conclusions. The observed effect was not sustained 12 months after the intervention.

\section{Implications for theory}

The results of this study provide limited support for the link between sickness absence and levels of control and support at work ${ }^{27}$ though, as has been noted, there are very few studies of interventions which have been developed on the basis of this theory. The fact that the impact of the intervention was not maintained over time highlights the need for an adequate length of post intervention follow up, and a more sophisticated design to enable consideration of additional factors that influence sickness absence rates in intervention studies such as this. Further work could replicate this study, using a design to allow the assessment of the relative contribution of each aspect of the intervention package to any changes that are observed.

\section{Implications for practice}

This study shows the acceptability among managers of the demand-control-support model as a framework for developing interventions to reduce staff sickness absence. It also shows the development of an intervention that is easy to implement as it is not dependent on a major investment of staff time. In addition, its evaluation is not dependent on self report measures, important for a service where many staff do not have English as a first language. Sickness absence is an accessible and discrete outcome measure with measurable financial outcomes, and is of interest from both a theoretical and practical perspective.

\section{Weaknesses of the study}

There are a number of ways in which this study could be improved. The use of sickness absence data provides a concrete outcome measure but was reliant on hospital records, the reliability of which was not independently validated. Using summary scores of sickness absence for a small, mobile workforce ignores the impact that a small number of staff with high absence levels may have on the study findings. There were also difficulties with the study sample. The staff groups in the study were non-equivalent, they were from only one hospital, there was substantial turnover, and the numbers of the "core" groups were small. The next step is for a multicentre, adequately powered trial of an intervention such as the one developed in this study. An economic evaluation should be included.

Since this study did not include self report measures, we were unable to assess staff perceptions of control and support, likely to be mediators between objective job changes and outcomes such as sickness absence. The study design did not allow the assessment of the active ingredients of this intervention. It could be that the temporary involvement of the occupational health service in redesigning aspects of the work of this staff group may in itself have had an impact. The study highlights the difficulties of developing methodologically rigorous organisational interventions in the context of NHS settings with high turnover and in services where access to individual self report is limited.

\section{Conclusion}

This study shows the development of an intervention that is acceptable to managers, feasible for use in health service staff groups with a variety of ethnic and language backgrounds and linked to an organisational outcome that is important in cost reduction. Previous work has highlighted the need for more studies of this kind which use an evidence based theoretical model to develop and evaluate interventions and use objective indicators of employee health. ${ }^{27}{ }^{28}$ The fact that the effect was small and not maintained over time shows the need for future research that is adequately powered to assess the impact of the different components of the intervention package, possible mediators, and long term maintenance of change. Larger studies could also investigate the impact of such interventions on different subgroups, including those who have frequent short term, rather than long term, sickness absence.

\section{ACKNOWLEDGEMENTS}

The authors would like to thank Dr Richard Morris, Royal Free and University College Medical School of University College London for his help with the statistical analyses, Stephen Bowyer, Workforce Systems and Information Manager, and Chris Perry, Cleaning Services Manager for their support for this study.

\section{Authors' affiliations}

S Michie, Centre for Outcomes Research and Effectiveness, Department of Psychology, University College London, London, UK

B Wren, S Williams, Occupational Health and Safety Unit, Royal Free Hampstead NHS Trust, London, UK

\section{REFERENCES}

1 Williams S, Michie S, Pattani S. Improving the health of the NHS workforce. London: The Nuffield Trust, 1998.

2 Confederation of British Industry. Managing absence: in sickness and in health. London: $\mathrm{CBI}, 1997$.

3 Barmby T, Ercolani G, Treble J. Sickness absence in Great Britain: new quarterly and annual series from the GHS and LFS, 1971-1997. Labour Market Trends 1999;August:405-15. 
4 NHS Executive. Human resources performance framework. London: HMSO, 2000.

5 Michie S, Williams S. Reducing psychological ill health and associated sickness absence: a systematic literature review. Occup Environ Med 2003:60:9-13.

6 Karasek RA. Job demands, job decision latitude, and mental strain: implications for job redesign. Admin Sci Quar 1979;24:285-311.

7 Kristensen TS. Sickness absence and work strain among Danish slaughterhouse workers - an analysis of absence from work regarded as a coping behaviour. Soc Sci Med 1991;32:15-27.

8 Firth $\mathrm{H}$, Britton P. Burnout, absence and turnover among British nursing staff. $J$ Occup Psychol 1989;62:55-9.

9 Gray-Toft PA, Andersen, JG. Organisational stress in the hospital: development of a model for diagnosis and prediction. Health Serv Res 1985; 19:753-74.

10 Barmby T, Ercolani G, Treble J. Sickness absence in Great Britain: new quarterly and annual series from the GHS and LFS, 1971-1997. Labour Market Trends 2000;August:405-15.

11 Briner R. Absence from work. In: Snashall D, ed. $A B C$ of work related disorders. London: BMJ Publishing Group, 1999.

12 Feeney A, North F, Head J, et al. Socioeconomic and sex differentials in reason for sickness absence from the Whitehall II study. Occup Environ Med 1998:55:91-8.

13 Blau G. Relationship of extrinsic, intrinsic and demographic predictors to various types of withdrawal behaviours. J Appl Psychol 1985;70:442-50.

14 North FM, Syme L, Feeney A, et al. Psychosocial work environment and sickness absence among British Civil Servants: the Whitehall II Study. Am J Public Health 1996:86:332-40.

15 Smulders PGW, Nijhuis,FJN. The job demands-job control model and absence behaviour: results of a 3-year longitudinal study. Work and Stress 1999; 13:115-31.

16 Stansfield SA, North FM, White I, et al. Work characteristics and psychiatric disorder in civil servants in London. J Epidemiol Community Health 1995;49:474-81.
17 Rael EGS, Stansfield SA, Shipley M, et al. Sickness absence in the Whitehall II study, London: the role of social support and material problems. J Epidemiol Community Health 1995;49:474-81.

18 Karasek RA. Demand/control model. In: Encyclopaedia of occupational health and safety. Geneva: ILO, 1997.

19 Karasek RA, Theorell T. Healthy work: stress, productivity and the reconstruction of working life. New York: Basic Books, 1990.

20 Johnson JV, Stewart W, Friedlund P, et al. Long-term psychosocial work environment and cardiovascular mortality among Swedish men. Am J Public Health 1996;86:324-31.

21 Unden AL. Social support at work and its relationship to absenteeism. Work and Stress 1996;10:46-61.

22 Vahtera J, Pentii J, Uutela A. The effect of job demands on registered sickness absence spells; do personal, social and job related resources act as moderators? Work and Stress 1996;10:286-308

23 Dwyer DJ, Gangster DC. The effects of job demands and control on employee attendance and satisfaction. Journal of Organisational Behaviour $1991 ; 12: 595-608$.

24 Marmot M, Siegrist J, Theorell T, et al. Health and the psychosocial environment at work. In: Marmot M, Wilkinson RG, eds. Determinants of health. Social determinants of health. New York: Oxford University Press, 1999:105-31.

25 Toivanen $\mathrm{H}$, Helin $\mathrm{P}$, Hanninen $\mathrm{O}$. Impact of regular relaxation training and psychosocial working factors on neck shoulder tension and absenteeism in hospital cleaners. J Occup Med 1993;35:1 123-30.

26 Whitaker S. New research into sickness absence. Human Resources in the NHS 1998;21:3.

27 Smulders PGW, Nijhuis FJN. The job demands-job control model and absence behaviour: results of a 3-year longitudinal study. Work and Stress 1999;13:115-31.

28 Dwyer DJ, Gangster DC. The effects of job demands and control on employee attendance and satisfaction. Journal of Organisational Behaviour $1991 ; 12: 595-608$. 